\title{
Editorial
}

\section{The 2030 Agenda for Sustainable Development}

The Asia Pacific is now arguably the world's most dynamic economic region. Bookended to the east and west by the world's most populous nations - China and India the region comprises a rich diversity of peoples, cultures and environments. The region's rapid economic transformation and expansion is increasingly viewed as a portent of the 'Asian Century', a term used to describe the likely dominance of Asian states in the twenty-first century. As the twentieth century was the 'American Century', and the nineteenth century the 'British Century', so the twenty-first century is witnessing the predominance of power from the Asia Pacific region.

The pivotal challenge for the Asian Century is addressing the entrenched poverty of many nations in the region while not irreparably degrading the regional and global environment upon which all of us depend. This dilemma is most starkly evident in relation to climate change. If the world is to meet the objective of the 2015 Paris Agreement ('holding the increase in the global average temperature to well below $2^{\circ} \mathrm{C}$ above pre-industrial levels') then China and India will need to pursue a path to development with only the slightest fraction of the carbon intensity of the North. This raises acute issues of intra- and inter-generational justice, and will inevitably require (if a fair and equitable outcome is to be achieved) the North to finance the transition of the Southern economies to carbon neutrality well before the end of the Asian Century.

Rapid economic development in the Asia Pacific has not only been visible because of its climate change implications, but also because of the many impacts it is having upon environments at local, national and regional levels. Managing these environmental impacts in the Asian Century is a central concern of the burgeoning body of environmental laws and policies that is being developed across the nations that are found in the Asia Pacific's diverse sub-regions of Southeast Asia, South Asia, East Asia, Polynesia, Oceania, Melanesia and Micronesia.

Since it was established in 1996, the Asia Pacific Journal of Environmental Law has documented these developments by publishing cutting-edge scholarship on all aspects of Asia Pacific environmental law. We are delighted that from 2016 APJEL will be published by Edward Elgar, with APJEL joining the award-winning publisher's growing catalogue of scholarly journals. We are also pleased to announce both an expanded Editorial Board, with additional leading scholars and practitioners from the region, and an expanded editorial team. In this inaugural Edward Elgar issue of $A P J E L$ we feature articles from a range of scholars across the region, together with reviews of recently published titles of particular salience for the Asia Pacific region.

In September 2015, all 193 Members of the United Nations adopted an ambitious new sustainable development agenda at the Sustainable Development Summit in New York: Transforming Our World - The 2030 Agenda for Sustainable Development. The 2030 Agenda for Sustainable Development is a plan of action that came into effect on 1 January 2016 and seeks to strengthen universal peace, eradicate 
poverty, and secure the Earth's environment through bold and transformative steps. We invited contributors to the first Edward Elgar volume of APJEL to examine the implications of the 2030 Agenda for Sustainable Development from the perspective of Asian Pacific environmental law.

In his article on illegal, unreported and unregulated (IUU) fishing, Juan He critically assesses the absence of a national strategy or legal framework in China for combatting this highly environmentally damaging activity. The argument is made that the failure of China to address IUU fishing undermines China's transition towards a sustainable and responsible fishing industry in China, which, by implication, also undercuts the 2030 Agenda which recognizes that social and economic development depends on the sustainable management of natural resources, including those in the oceans and seas. He argues for a 'strategic overhaul' that would see the introduction of a comprehensive legal framework to combat IUU fishing directly engaged in, or supported by, Chinese fishing interests.

One of the consequences of rapid economic development, population growth, and urbanization, and also a changing regional and global environment is the exposure of hundreds of millions of people in the Asia Pacific to the risk of disasters (be such disasters natural, induced by man, or a combination of the two). Disaster risk reduction is highlighted in several of the 17 goals of the 2030 Agenda (Goals 11 and 13 especially). Howard Kunreuther and Rosemary Lyster begin their article by noting the serious impacts of climate-induced disasters in the Asia Pacific region, highlighting the floods in Pakistan in 2010. Drawing from the North American experience, they explain the potential for the insurance market to be used to address disaster risk in the Asia Pacific region, presenting Thailand's National Disaster Fund as an example. Their article offers valuable insights into how insurance can be used effectively, if designed appropriately, to share the burdens of natural disaster risk, and provide support for the most vulnerable victims of extreme weather events.

One of the consequences of growing and moving populations, and increased urban and agricultural development in the Asia Pacific region, has been the increasing challenge of dealing with invasive species. In a piece situated against the backdrop of the 2030 Agenda, Elodie Le Gal anticipates and assesses the challenges arising in Australia from the use of biofuel crops that also pose an invasive weed risk. The Paris Climate Agreement goals are only likely to be achieved if there is rapid and extensive replacement of fossil fuels in transportation with low-carbon alternatives, including biofuels. Yet the development of biofuels has significant implications for landscapes and biodiversity, including because of the invasive characteristics of some biofuel crops. Drawing on several theoretical perspectives, Le Gal proposes a governance framework for managing this risk.

The threat posed by climate change permeates the 2030 Agenda as an overarching challenge for planetary environmental stability. Benoit Mayer's article on the noharm principle and climate change introduces a novel angle to debates over the content of the climate regime as it is set out in the 1992 United Nations Framework Convention on Climate Change and subsequent agreements, including most notably and recently the Paris Agreement. Noting that the no-harm principle (that states have the responsibility to ensure that activities within their jurisdiction/control do not cause damage to other states) is the cornerstone norm of international environmental law, Mayer explores ways in which the principle could be applied, in a flexible way, to provide remedial obligations to address climate change. He argues that the principle is a better candidate as an organizing concept for climate negotiations than the concept of common but differentiated responsibility, which, he argues, says little about how individual state 
liabilities should be conceived. The no-harm principle therefore provides a constructive way forward for structuring the ongoing development of the climate regime.

Burton Ong, Lye Lin-Heng and Joseph Chun critically assess the legal frameworks that have been developed in South East Asia and Singapore in an effort to arrest rapidly declining biological diversity across the region. Their article maps the developments within ASEAN to promote biodiversity conservation, against the background of the international commitments that ASEAN states have assumed under the 1992 Convention on Biological Diversity and the 1973 Convention on International Trade in Endangered Species of Wild Fauna and Flora. They explain how biodiversity conservation is conceptualized in the region as a goal that is integral to policies for achieving sustainable development. However, they identify a number of major challenges, including the lack of harmonization among the ten national biodiversity laws in effect. They argue that one response to this is to 'foster a regional cultural identity connected to tropical diversity'.

Moving westwards, Bill Pritchard offers an insightful commentary on India's profound challenges in meeting the goals of the 2030 Agenda, while at the same time neither undermining its national environment, nor contributing disproportionately to global environmental decline, especially as regards climate change. Pritchard examines India's acute vulnerability to climate change impacts, particularly possible shifts in the timing of the annual monsoon, and the flow-on effects of this for food insecurity. Set against these impacts, Pritchard then considers India's rising (though currently still small) contribution to climate change, and notes that India is destined to walk a fiendishly challenging tightrope between promoting development while also promoting action on climate change. Whether India is able to achieve this has not just national and regional, but also global, implications given the unfolding climate change crisis.

In this inaugural Edward Elgar volume of $A P J E L$ we are also pleased to feature four reviews of recent books of direct relevance and interest to scholars and practitioners of environmental law in the Asia Pacific region.

As editors, and on behalf of our editorial team, we look forward to APJEL's continued contribution to environmental jurisprudence in the Asia Pacific region, and indeed globally, through the publication of quality research that anticipates and responds to developments in this exciting and vitally important field.

Tim Stephens and Ed Couzens Editors, University of Sydney, Australia 